\title{
BIOSECURITY IN A BRAZILIAN PUBLIC DENTAL UNIT
}

\author{
L.F. JESUS \& F.R. MOREIRA \\ National School of Public Health, Oswaldo Cruz Foundation, Brazil.
}

\begin{abstract}
This study evaluated biosecurity procedures and management of infectious/sharps waste adopted by 13 dentists and 5 dental assistants in their daily routines in ambulatory care. The data were obtained through a simple observation method, a self-administered questionnaire, and conversations with the subjects under study. Results indicated a complete lack of awareness to biosecurity especially among male dentists and assistants. Most dentists used appropriate personal protective equipment while assistants were apparently unaware of biosecurity practices. Infectious and sharp residues were not disposed of properly and the poor ventilation was a major problem. Despite the flaws, the work was organised in such a way as to provide professionals with good working conditions. Routine exposure trivialises the occupational risks for dental professionals. Encouraging prevention and security actions can contribute to a healthier and safer workplace.
\end{abstract}

Keywords: Dentistry, infectious and sharps waste, management practices, occupational health, personal protective equipment.

\section{INTRODUCTION}

The dental practice can pose several risks to the health of dentists, their assistants and patients. Such risks may lead to occupational diseases capable of impairing the quality of life of these individuals throughout their different life stages. Consequently, modern odontology requires professionals to be aware of the importance of biosecurity in the control of the operational hazards inherent to the exercise of the profession [1,2].

In general, biosecurity involves practices, procedures and use of equipment necessary to ensure proper security conditions in all environments where one handles potentially infectious microorganisms and other biological hazards [3]. In dentistry, it refers to the set of actions employed to protect staff and patients against infectious hazards in a clinical setting [1].

The dental activity produces infectious, sharps and chemical waste, besides the regular trash. Among those infectious, the risk is related to the gauze, cotton rolls, gloves and other materials used on patient care and disposed of in regular waste. The sharps waste includes needles, syringes, scalpels, drills, blades, endodontic files and orthodontic wires [4].

Dentists and dental assistants are exposed to a large number of microorganisms from the oral cavity of patients [5]. The use of devices generating aerosols usually aggravates such a situation since they can spread microorganisms for distances of up to $1 \mathrm{~m}$ around the operating field [6]. There is also the contamination of the dental equipment, which can remain infected for long periods due to the high survival of some pathogens, representing a health risk to patients and dental professionals [7].

The most common diseases cited as major risks for dentistry are hepatitis B, C \& D, acquired immunodeficiency syndrome (AIDS), influenza, herpes, tuberculosis, measles, mumps, rubella [2,8-10]. The same routine for the infection control should be adopted for all patients since carriers of latent infections cannot be identified [5]. Once no vaccines are available for preventing hepatitis C and AIDS, such diseases become especially dangerous for those exposed as well as the potential transmission of virus in dental offices through blood and other body fluids cannot be ignored. In an attempt to avoid contamination with 
pathogenic microorganisms during the dental practice, it is important to follow an infection control protocol. Preventive measures include careful handling of potentially contaminated materials, minimising the formation of drops, splashes and aerosols [7,11], hand-hygiene practices, disinfection of the equipment and environment, sterilisation of the instruments, antisepsis of the mouth of the patient and use of personal protective equipment (PPE) by the professional and team. Such precautions are essential for a safe practice of the oral health for both patients and practitioners [11,12].

The PPEs suggested for use in dental care facilities are gloves for clinical and surgical work, discarded after every patient has been treated; caps; protective clothing, disposable masks (double layer or triple) and goggles. To prevent the transmission of contaminants among environments, closed-toe shoes should be worn in the clinic. The PPEs provide physical barriers to protect the skin and mucous membranes of eyes, nose and mouth from exposure to potential sources of contamination during dental procedures [13].

Risks and costs resulting from treatment and safe disposal of such waste could be minimised with waste management programs including the separation and identification according to their classification as well as a proper storage inside the institution and forwarding to final disposal as per the waste classification. Improper disposal of such waste, no information on risks posed, inadequate training for their management as well as the lack of financial and human resources for this activity can lead to accidents and contamination, with harm to human health and environment [4].

This study aimed at investigating biosecurity actions adopted by dentists and dental assistants during their professional routines in the clinic and the disposal of infectious and sharps waste.

\section{METHOD}

The study was carried out in a public health centre (PHC), administered by the government of Rio de Janeiro, Brazil. Eighteen professionals worked at the dental clinic, chosen for its quality in the organisation of dental care as well as providing services to the population, both considered as references. All the 13 dentists and 5 assistants agreed in participating of this research.

The participants answered a self-filling questionnaire which aimed at knowing socialdemographic variables, general morbidity, pathological and occupational histories, and lifestyle as well as the habits of biosecurity of the professionals during their working hours. The simple observation method was used associated to the information obtained through the questionnaire and conversations with the subjects of study to find whether the procedures adopted in the outpatient clinic complied with the biosecurity standards for health assistance environments. The way of managing the infectious and sharps waste generated in the dental offices was investigated on the basis of the recommendations established by the World Health Organisation (WHO) [14].

The chief of the dental clinic authorised the visits of the researcher to the dental offices. She indicated that dental staff would perform practices as usual routine work. Her aim was to improve the security of the workers, since this dental clinic was already considered as an example for its quality in the organisation of dental care among public dental clinics. It was assumed in this study that dental staff performed as usual their routine work.

Ethics Committees in Research from the National School of Public Health/Oswaldo Cruz Foundation and Bureau of Health and Civil Defence of Rio de Janeiro City gave permission for developing the research. An informed consent form was obtained from each participant. 


\section{RESULTS AND DISCUSSION}

\subsection{Population of study}

The study population consisted of 18 individuals, including 13 dentists and 5 dental assistants. Most participants were female (67\%). The average time of working as a dentist was nearly twice $(97.78 \%)$ of that presented by the assistants. However, the auxiliaries had slightly higher mean age (11\%) than the dentists. Regarding the PPEs, nine dentists $(69.2 \%)$ wore all of them regularly, while only one assistant (20\%) wore all protective equipment, although safe practice recommendations address equally both dentists and assistants. Table 1 shows the data related to the populations studied.

Unlike the research conducted by Hashim et al. [15] in which men were the majority $(61 \%)$, female dentists had the highest participation in this study $(62 \%)$. However, similarly all dentists were over 10 years of professional practice in both studies. According to the European Agency for Safety and Health at Work [16], the process of feminisation of the labour market and the ageing of the active population have introduced a new dimension in the subject of health and safety at work since preventive measures must take into account the risks to which these special groups are particularly susceptible.

The concern over the risk of hepatitis B virus infection was properly addressed since all dentists $(100 \%)$ and auxiliary $(100 \%)$ had been vaccinated as in the research of Hashim et al. [15]. Despite some publications, Araujo and Andreana [17] emphasise that dental workers have an increased risk of becoming a carrier of hepatitis B regarding non-exposed population, just $60 \%$ of participants were protected against such a disease in United Arab Emirates [15] and only $10.75 \%$ in Palestine [18].

In this study, dentists and assistants did not know all the sanitary legislation on waste management for health-care activities as well as failed to comply with those which were of their knowledge. However, several authors have reported the ignorance and negligence of dentists and assistants related to protocols for managing the waste generated in the offices [4].

\subsection{Biosecurity}

The PHC provided the professionals with latex gloves (non-sterile and sterile), caps, masks and protective eyewear as well as liquid soap dispensers and disposable paper towels. Studies have demonstrated that the majority of patients felt confident with dental professionals who took security measures to safeguard both health of dental healthcare workers and patients $[19,20]$.

Table 1: Description of the study population.

\begin{tabular}{lcc}
\hline Gender & Dentists $(n=13)$ & Assistants $(n=5)$ \\
\hline Male & $5(38 \%)$ & $1(20 \%)$ \\
Female & $8(62 \%)$ & $4(80 \%)$ \\
Mean age (years) & 42.4 & 47.2 \\
Mean working time (years) & $16.2(10-25)^{*}$ & $8.2(2-20)^{*}$ \\
Use of all PPEs & $9(69.2 \%)$ & $1(20 \%)$ \\
\hline
\end{tabular}

*(range); PPE, personal protective equipment. 
The first guidelines for use of barriers to infection control in dental practices were published in 1986 by the Center for Disease Control and Prevention (CDC) [21]. Since the introduction of such rules, dentists have increased the use of PPEs while the level of bacterial contamination in dental offices has decreased [22,23]. However, studies reporting a small number of dental workers using such equipment are still common [24,25].

Among dentists in this study, women wore all PPEs suggested for the profession from those provided by PHC up to equipment purchased for their own use. On the other hand, men were more neglectful in this regard since just one among eight male dentists made proper use of PPE required when working with patients. In the group of assistants, only one woman wore all appropriate PPEs while another worked with no protection.

Studies have emphasised the need for educative campaigns to increase the awareness and use of PPEs during the dental practice and thus control the risk of infection [24,26,27]. Training and continued education are also important to update the knowledge of dental professionals, especially due to the emergence of new pathogens, re-emergence of variant organisms and more patients seeking care in dental care facilities [12,28]. According to the British Dental Association [5], all dental workers should know the procedures required for preventing the transmission of infection and why they are necessary.

In our study, all dentists $(100 \%)$ wore surgical masks during patient-care procedures. However, they did not change the masks as prescribed by the Center for Disease Control and Prevention [13], wearing the same one throughout the working day. The dentists did not follow the recommendations for changing masks after every patient or even during the care in case of wetting with blood or other secretions. All assistants worked without masks in the same room of patients and dentists.

All the dentists washed their hands and changed the gloves after each patient, providing protection for themselves and patients. A study showed that although dental workers recognised the need to wash hands, they did not so [25]. Gloves and masks are used in a high proportion by dentists according to researches on biosecurity in dentistry [26,27,29].

In this study, 11 dentists $(84.6 \%)$ wore safety glasses during the patient care. Such a high percentage is probably related to the dentists' awareness of gloves and glasses use. This is opposite to other studies which have reported a low incidence in the use of protective eyewear $[6,25-27,29]$. Among dentists who had already experienced an ocular injury or infection in a Jordanian study, $73 \%$ were not wearing an eye protection [30].

In the dental clinic studied, nine dentists (69.2\%) and two assistants (40\%) usually wore surgical caps. According to the University of Arkansas for Medical Sciences [31], the use of such a PPE prevents aerosol droplets from the high-speed motor and prophylaxis devices as well as the mercury from dental amalgam to come into contact with the hair and scalp, preventing them from becoming sources of contamination.

Twelve dentists $(92.3 \%)$ and four assistants $(80 \%)$ wore scrubs. However, just one dentist wore short-sleeve scrubs while all the others wore long-sleeve ones. Once again, our findings were the opposite of other studies since most of the dental workers wore appropriate protective clothing. Some research showed high percentages of such workers who did not wear protective gowns during dental procedures [25,26], favouring the accumulation of contaminants on the street clothes and skin of the professionals.

All dentists (100\%) wore enclosed footwear, but they were not exclusively for use during the care to the patients. Two assistants $(40 \%)$ wore closed-toe shoes and the other assistants wore sandals. The UK Department of Health [12] recommends the enclosed footwear in order to protect against injuries and spillage of hazardous products onto feet. 
Only instruments sterilised were used during the patient care. Inadequate sterilisation $[32,33]$ or cases of non-sterilised instruments [25,34] before using on another patient are common in dentistry. Piazza et al. [35] reported that the risk of contamination by infectious agents has increased with an inappropriate sterilisation.

In our study, dentists disinfected surfaces such as high- and low-speed hand pieces, air water syringes, handles from dental lights and X-ray equipment with $70 \%$ alcohol after every patient. On the other hand, those surfaces were coated with PVC film, removed and discarded before using on the next patient. According to the British Dental Association [5], the barrier used for the protection of surfaces and equipment in the site of study was appropriate. Studies showed that surfaces of a dental clinic may be reservoirs for pathogenic microorganisms [32,36].

The ventilation inside the clinic did not follow the standards recommended for such a kind of work [5,37]. The workplace had no windows or swivelling panels. Access doors to the outpatient clinic were the only way of ventilation. Also, the walls were too high $(5.1 \mathrm{~m})$ and the air-conditioning units were close to the ceiling. Thus, air filtering elements of those units were not cleaned or replaced. This unhealthy situation has potentially increased the risks of both chemical and biological exposure in the workplace. A similar condition was reported wherein $96.4 \%$ of the dentists surveyed did not replace periodically the filters in the air-conditioning units, thereby raising the likelihood of indirect exposure to contaminants in the indoor environment [29]. However, dental clinics investigated by Godwin et al. [38] presented ventilation within acceptable standards.

Institutions regulating the public health [12] and practice of dentistry [5] state that suitable ventilation allows the rapid dispersion of contaminants in the air, reducing the exposure of the worker in the workplace. Mechanical ventilation systems should provide an input stream of air and prevent recirculation of microorganisms [5,12]. Such systems are advantageous for places that aim at achieving the requirements of good practice, although they can be expensive while the natural ventilation in clinical areas is considered advantageous as to the necessary capital and operating costs [12].

\subsection{Infectious and sharps waste}

Pathogenic microorganisms existing in infectious waste can survive for days, months or years in the trash, posing a potential health risk to the public and environment. Thus, the contact of these pathogens with humans can cause infections in the gastrointestinal tract, respiratory tract, eyes and skin as well as meningitis, AIDS, hepatitis, avian influenza, among others [4].

The materials used during the patient care such as sucker tubes, anaesthetic tubes, masks, gloves, gauze, cotton balls, etc. were disposed of into the regular bin. Such waste should be discarded in bins lined with yellow plastic bags, leak-proof, and labelled as 'contaminated' $[14,39]$. However, that practice was not observed in our research neither in other studies [40,41].

According to the WHO [42], sharps waste poses a great risk of contamination with hepatitis $\mathrm{B}$ and $\mathrm{C}$ virus, as well as HIV/AIDS for healthcare professionals. In general, sharps injuries involve needles, especially during recapping needles and collecting waste. However, such needle stick injuries can be reduced when safer syringes and intensive training of the staff are provided. Once those accidents are unexpected, the periodic training of workers exposed is necessary for raising awareness and preventing their occurrence [4].

All dental offices had yellow cardboard boxes labelled with the universal biohazard symbol for collection of sharps. On routine basis, it was found that after completing two-third of 
their capacity, an employee from the cleaning staff closed and sent the containers to a special dump in the PHC, where the disposal of the material was suitable. Although the collection boxes were always replaced before being overfilled, their closing was not in accordance with health regulations since special training is required for cleaning staff [43]. Sharps wastes were properly packed in $73.3 \%$ of the sites investigated in New Zealand [44] and $60 \%$ of dental offices studied in Brazil [45], while only $13.5 \%$ of 37 dental clinics investigated in Palestine adopted such a practice [18].

\section{CONCLUSIONS}

The routine exposure to biological hazards at work became common place for dental professionals, trivialising the biosafety in the outpatient clinic, especially among male dentists and assistants as well. Periodic professional training would help the staff being aware of the risks posed by the occupational exposure and the importance of proper disposal of waste produced.

Despite some flaws identified in the management of waste, the place offered good working conditions, besides contributing to the improvement of the oral health in a significant way. Improvements in prevention and biosafety will mainly contribute to a healthier and safer workplace for dental professionals and patients.

\section{ACKNOWLEDGEMENT}

The authors thank the Foundation for Support to Research in the State of Rio de Janeiro (FAPERJ) for the financial support.

\section{REFERENCES}

[1] Occupational Safety \& Health Administration (OSHA), Dentistry, available at http://www.osha.gov/SLTC/dentistry/standards.html

[2] Leggat, P.A., Kedjarune, U. \& Smith D.R., Occupational health problems in modern dentistry: a review. Industrial Health, 45(5), pp. 611-621, 2007. doi: http://dx.doi. org/10.2486/indhealth.45.611

[3] United States Department of Health and Human Services (HHS/PHE), Public Health Emergency Science, Safety, Security - Finding the Balance Together, available at http://www.phe.gov/s3/faqs/Pages/biosafety.aspx

[4] Moreira, F.R. \& Jesus, L.F., Medical waste management in a dental clinic. WIT Transactions on Biomedicine and Health, 16, 2013, ISSN 1743-3525.

[5] British Dental Association (BDA), Infection Control in Dentistry, BDA Advice Sheet A12, available at http://webarchive.nationalarchives.gov.uk/20130107105354/http:// www.dh.gov.uk/en/Publicationsandstatistics/Publications/PublicationsPolicyAndGuidance/DH_4120904?IdcService=GET_FILE\&dID=7205\&Rendition=Web

[6] Askarian, M., Mirzaei, K. \& Cookson B., Knowledge, attitudes, and practice of iranian dentists with regard to HIV-related disease. Infection Control \& Hospital Epidemiology, 28(1), pp. 83-87, 2007. doi: http://dx.doi.org/10.1086/509851

[7] Thomas, M.V., Jarboe, G. \& Frazer, R.Q., Infection control in the dental office. The Dental Clinics of North America, 52(3), pp. 609-628, 2008. doi: http://dx.doi.org/10.1016/j. cden.2008.02.002

[8] American Dental Association (ADA), Oral Health Topics, Tuberculosis, ADA: Chicago, 2011, available at http://www.ada.org/2755.aspx 
[9] American Dental Association (ADA), ADA Research Institute - Research on Emerging Issues, available at http://www.ada.org/6166.aspx\#top

[10] McCarthy, G.M., Risk of transmission of viruses in the dental office. Journal of Canadian Dental Association, 66(10), pp. 554-557, 2000.

[11] Kohn, W.G., Harte, J.A., Malvitz, D.M., Collins, A.S., Cleveland, J.L. \& Eklund, K.J., Centers for Disease Control and Prevention. Guidelines for Infection Control in Dental Health-Care Settings — 2003, available at http://www.cdc.gov/mmwr/preview/ mmwrhtml/rr5217a1.htm

[12] United Kingdom Department of Health (DH), Decontamination Health Technical Memorandum 01-05: Decontamination in Primary Care Dental Practices, available at https://www.gov.uk/government/uploads/system/uploads/attachment_data/file/170689/ HTM_01-05_2013.pdf

[13] Centers for Disease Control and Prevention (CDC), Infection Control in Dental Settings - Personal Protective Equipment (Masks, Protective Eyewear, Protective Apparel, Gloves), available at http://www.cdc.gov/oralhealth/infectioncontrol/faq/protective_equipment.htm doi: http://dx.doi.org/10.1007/bf01728895

[14] World Health Organization (WHO), Safe Management of Wastes from Healthcare Activities, available at http://www.who.int/water_sanitation_health/medicalwaste/ wastemanag/en/

[15] Hashim, R., Mahrouq, R. \& Hadi, N., Evaluation of dental waste management in the Emirate of Ajman, United Arab Emirates, Journal of International Dental and Medical Research, 4(2), pp. 64-69, 2011.

[16] European Agency for Safety and Health at Work (EU-OSHA), Community Strategy on Health and Safety at Work 2002-2006, available at http://eur-lex.europa.eu/smartapi/ cgi/sga_doc?smartapi!celexplus!prod!DocNumber\&lg=en\&type_doc=COMfinal\&an_ doc $=2002 \&$ nu_doc $=118$

[17] Araujo, M.W. \& Andreana, S., Risk and prevention of transmission of infectious diseases in dentistry. Quintessence International, 33(5), pp. 376-382, 2002.

[18] Darwish, R.O. \& Al-Khatib, I.A., Evaluation of dental waste management in two cities in Palestine. Eastern Mediterranean Health Journal, 12(Suppl 2), pp. S217-S222, 2006.

[19] McKenna, G., Lillywhite, G.R.R. \& Maini, N., Patient preferences for dental clinical attire: a cross-sectional survey in a dental hospital. British Dental Journal, 203(12), pp. 681-685, 2007. doi: http://dx.doi.org/10.1038/bdj.2007.1109

[20] Shulman, E.R. \& Brehm, W.T., Dental clinical attire and infection-control procedures. Patients' attitudes. Journal of American Dental Association, 132(4), pp. 508-516, 2001. doi: http://dx.doi.org/10.14219/jada.archive.2001.0214

[21] Centers for Disease Control and Prevention (CDC), Recommended Infection-Control Practices for Dentistry, available at http://www.cdc.gov/mmwr/preview/mmwrht$\mathrm{ml} / 00033634 . \mathrm{htm}$

[22] Hazelkorn, H.M., Bloom, B.E. \& Jovanovic, B.D., Infection control in the dental office: has anything changed? Journal of American Dental Association, 127(6), pp. 786-790, 1996. doi: http://dx.doi.org/10.14219/jada.archive.1996.0315

[23] Williams, H.N., Singh, R. \& Romberg, E., Surface contamination in the dental operatory: a comparison over two decades. Journal of American Dental Association, 134(3), pp. 325-330, 2003. doi: http://dx.doi.org/10.14219/jada.archive.2003.0161 
[24] Sağlam, A.M. \& Sarikaya, N., Evaluation of infection-control practices by orthodontists in Turkey. Quintessence International, 35(1), pp. 61-66, 2004.

[25] Mehtar, S., Shisana, O., Mosala, T. \& Dunbar, R., Infection control practices in public dental care services: findings from one South African Province. Journal of Hospital Infection, 66(1), pp. 65-70, 2007. doi: http://dx.doi.org/10.1016/j.jhin.2007.02.008

[26] Puttaiah, R., Shetty, S., Bedi, R. \& Verma, M., Dental infection control in India at the turn of the century. World Journal of Dentistry, 1(1), pp. 1-6, 2010. doi: http://dx.doi. org/10.5005/jp-journals-10015-1001

[27] Öztürk, M., Özeç, I. \& Kiliç, E., Utilisation of personal protective equipment in dental practice. International Dental Journal, 53(4), pp. 216-219, 2003. doi: http://dx.doi. org/10.1111/j.1875-595x.2003.tb00748.x

[28] Harte, J.A., Standard and transmission-based precautions: an update for dentistry. Journal of American Dental Association, 141(5), pp. 572-581, 2010. doi: http://dx.doi.org/ 10.14219/jada.archive.2010.0232

[29] Kulkarni, S., Tadakamadla, S.K., Jain, K., Goyal, D., Balasubramanyam, G. \& Duraiswamy, P., Mercury hygiene practice among practicing dentists and undergraduate dental students of India. Revista de Clínica e Pesquisa Odontológica, 4(1), pp. 19-26, 2008.

[30] Othman, E.F., Eye safety in dentistry — a study. Pakistan Oral \& Dental Journal, 30(1), pp. 8-13, 2010.

[31] University of Arkansas for Medical Sciences, College of Health Related Professions (UAMS-CHRP), Exposure Control: Before Patient Treatment, available at http://www. uams.edu/chrp/dentalhygiene/exposurecontrol/BeforePatientTreat.ment.asp

[32] Zhou, L., Zhu, H., Lin, J., Hu, M., Chen, F. \& Chen, Z., Surveillance of viral contamination of invasive medical instruments in dentistry. Journal of Zhejiang University Science B, 7(9), pp. 745-748, 2006. doi: http://dx.doi.org/10.1631/jzus.2006.b0745

[33] Scottish Executive (NHSScotland), NHSScotland: Sterile Services Provision Review Group Survey of Decontamination in General Dental Practice, available at http://www. scotland.gov.uk/Resource/Doc/26800/0012665.pdf>

[34] FOXNews.com, Thousands ofOklahomapatientsurged togettested forHIV, hepatitis after investigation shows dirty instruments in use, Published 29 March 2013, available at http:// www.foxnews.com/health/2013/03/29/thousands-oklahoma-dental-patients-urgedto-get-tested-for-hiv/

[35] Piazza, M., Borgia, G., Picciotto, L., Nappa, S., Cicciarello, S. \& Orlando, R., Detection of hepatitis $\mathrm{C}$ virus-RNA by polymerase chain reaction in dental surgeries. Journal of Medical Virology, 45(1), pp. 40-42, 1995. doi: http://dx.doi.org/10.1002/ jmv.1890450108

[36] Roberts, M.C., Soge, O.O., Horst, J.A., Ly, K.A. \& Milgrom, P., Methicillin-resistant Staphylococcus aureus from dental school clinic surfaces and students. American Journal of Infection Control, 39(8), pp. 628-632, 2011. doi: http://dx.doi.org/10.1016/j.ajic .2010 .11 .007

[37] Government of Alberta, Handbook of Occupational Hazards and Controls for Dental Workers, available at http://humanservices.alberta.ca/documents/OHS-WSA-handbook-dental-workers.pdf

[38] Godwin, C.C., Batterman, S.A., Sahni, S.P. \& Peng, C.Y., Indoor environment quality in dental clinics: potential concerns from particulate matter. American Journal of Dentistry, 16(4), pp. 260-266, 2003. 
[39] World Health Organization (WHO), Waste from Health-Care Activities, available at http://www.who.int/mediacentre/factsheets/fs253/en/

[40] Sood, A.G. \& Sood, A., Dental perspective on biomedical waste and mercury management: a knowledge, attitude, and practice survey. Indian Journal of Dental Research, 22(3), pp. 371-375, 2011. doi: http://dx.doi.org/10.4103/0970-9290.87055

[41] Koolivand, A., Mahvi, A.H., Alipoor, V., Azizi, K. \& Binavapour, M., Investigating composition and production rate of health care waste and associated management practices in Bandar Abbass, Iran. Waste Management Research, 30(6), pp. 601-606, 2012. doi: http://dx.doi.org/10.1177/0734242x11416037

[42] World Health Organization (WHO), Sharps Injuries: Global Burden of Disease from Sharps Injuries to Health-Care Workers, available at http://www.who.int/quantifying ehimpacts/publications/9241562463/en/

[43] National Institute for Occupational Safety and Health (NIOSH), Selecting, Evaluating, and Using Sharps Disposal Containers, available at http://www.cdc.gov/search. do? $\mathrm{q}=$ Selecting $\% 2 \mathrm{C}+$ Evaluating $\% 2 \mathrm{C}+$ and+using+Sharps+Disposal+Containers\&sp ell $=1 \&$ ie $=$ utf 8

[44] Treasure, E.T. \& Treasure, P., An investigation of the disposal of hazardous wastes from New Zealand dental practices. Community Dentistry and Oral Epidemiology, 25(4), pp. 328-331, 1997. doi: http://dx.doi.org/10.1111/j.1600-0528.1997.tb00948.x

[45] Lima Neto, J.F., Pinheiro, F.M., Nobrega-Therrien, S.M. \& Pinheiro, V.C., Solid waste management in private dental practices. Revista Gaúcha de Odontologia, 60(1), pp. 33-39, 2012. 